American Journal of Economics and Business Administration 2 (1): 73-77, 2010

ISSN 1945-5488

(C) 2010 Science Publications

\title{
The Productivity and Human Capital in the Japanese Software Industry: The View of Service Innovation
}

\author{
Kazunori Minetaki and Toshihiko Takemura \\ The Research Institute for Socionetwork Strategies, Kansai University, \\ 3-3-35, Yamate-Cho, Suita, Osaka, Japan, 564-8680
}

\begin{abstract}
Problem statement: It has been pointed out the weak competitiveness of Japanese software industry. The industrial characteristic of the software industry in Japan is the subcontract system. There are numerous pieces of anecdotal evidence suggesting that the Japanese software industry suffers from low productivity growth on a par with that of other non-manufacturers particularly those in the services sector. In addition, there are not enough empirical studies of the productivity in the Japanese software industry. Approach: We analyze the productivity of the Japanese software industry in the view of the hierarchy structure and we investigate the effect to adopt the Information Technology Engineers Examination for the acquirement of knowledge of software development by using Cobb-Douglas Production Function. Results: Our main result is that the human capital measured by the Information Technology Engineers Examination for the acquirement of knowledge of software development, has the positive correlation with the productivity in the subcontractor companies, but not in the contractor companies. Conclusion/Recommendations: Our estimation result implies that the accumulation of the human capital is helpful to raise the productivity in subcontractor and it will bring the higher productivity in the software industry as the whole in Japan.
\end{abstract}

Key words: Productivity, human capital, service innovation, software industry, information technology engineers examination

\section{INTRODUCTION}

The software industry is a kind of the high knowledge intensive industries and so to investigate the software industry brings us the important idea considering the innovation on service. There are many resources of innovation, for example, $\mathrm{R} \& \mathrm{D}$ investment, patent, human capital and networking to other companies or research institutes.

On the other hand, it has been pointed out the weak competitiveness of Japanese software industry. There are numerous pieces of anecdotal evidence suggesting that the Japanese software industry suffers from low productivity growth on a par with that of other nonmanufacturers particularly those in the services sector. For example, not a single Japanese firm had attained the highest rank under the internationally-recognized Capability Maturity Model (CMM) as of the end of 2000, whereas some 23 Indian firms had achieved this status. A system for appraising the maturity or capability of organizations engaging in software development that was developed by Carnegie Mellon University at the request of the US Department of
Defense. Originally intended as a tool to evaluate the ability of government contractors, the CMM is now also used by private-sector firms that have no direct involvement in government procurement. Worldwide some 7,400 software development projects in more than 40 different countries have already been evaluated using the CMM. India has made the development of its software industry a national priority and as of the end of 2,000 Indian firms accounted for a significant proportion of top-ranking companies, with 23 firms assessed as "maturity level five" and a further 24 evaluated as "maturity level four".

Now the software industry are facing the structural change and struggling with the global competition. The characteristic of Japanese software industry is the hierarchy structure that the contractor usually out sources the development of software to the subcontractor. The famous main contractors are Hitachi, NEC and Fujitsu in Japan. Those companies have been also providers of computer hardware and they have been predominant in the Japanese software industry. In the era of mainframe computer, the software was not separated with the hardware. In Japan, the Information

Corresponding Author: Kazunori Minetaki, The Research Institute for Socionetwork Strategies, Kansai University, 3-3-35, Yamate-Cho, Suita, Osaka, Japan, 564-8680 
and Communication Technology (ICT) vendors provide both the hardware and the software today. So the share of custom software sales is largest in the Japanese software industry.

The first structural change is the diffusion of internet. The old type of skill of software development which was standard in mainframe computer becomes obsolete and is replaced to the web based technology. It brings the big chance to the new companies which have emerged after the internet diffused. The programmers do not need to have the skill of old type of technology in developing web based software. Also internet brings new service named Software as a Service (SaaS). Provider distributes the software service by internet and user companies do not need to buy or develop software. There is no longer comparative advantage in ICT vendor which have been predominant in the Japanese software industry for the long time.

Secondly, the open software like Linux changes the rigid structure of Japanese software industry. New companies can more easily enter using open software especially in OS because the source code is open and so everyone can develop application software. The share of Linux has been increased in OS market in Japan. Open software has the power to change the hierarchy industry structure where major ICT vendors predominated.

Thirdly, offshore development has changed the Japanese software market. China and India are offshore for Japan. There are cheap and high skilled programmers in those countries. Japanese companies outsource the development of software to those countries. It means the decrease of jobs in the domestic market in Japan. So, offshore development attacks the subcontract structure in the Japanese software industry.

We analyze the productivity of the Japanese software industry in the view of the hierarchy structure and we investigate the effect to adopt the Information Technology Engineers Examination for the acquirement of knowledge of software development.

There are not enough empirical studies of the productivity in the Japanese software industry.

Nishimura and Minetaki (2004) focus on two possible determinants of productivity in the Japanese information services industry which is mainly consisted of the software industry: (1) modularization and (2) economies of scale. Baldwin and Clark (1997) argue that the biggest difference between module suppliers and ordinary subcontractors is that the former enjoy much greater freedom to experiment with product designs, writing: "For an industry like computers, in which technological uncertainty is high and the best way to proceed is often unknown, the more experiments and the more flexibility each designer has to develop and test the experimental modules, the faster the industry is able to arrive at improved versions". In other words, it should be possible for even relatively small firms to play a leading role in modularization provided that they remain independent from major vendors and for outsourcing arrangements between such firms to have a positive impact on productivity. The concept of "modularization" which is credited with having brought about dramatic productivity gains over the past few decades-dates back to the development of the IBM System/360 mainframe computer family and refers to the construction of complex systems consisting of small, independently designed subsystems as modules based on an "architecture" describing their interrelationships with interface elements and internal structural elements considered separately. Outsourcing by firms in the information service industry can be considered a form of "organizational modularization". After describing their data set and some of its inherent limitations, they present the results of empirical analysis aimed at clarifying the extent to which productivity in the Japanese information services industry has been influenced by modularization and development scale. The results show that the ratio of outsourcing costs to total sales has actually had a negative impact on productivity for the industry as a whole. They attribute this phenomenon to insufficient modularization of the development and production processes, which makes it very difficult for project managers to provide the necessary interfaces between modules.

Their results also point to the existence of diseconomies of scale, with an increase in the number of system engineers tending to have a negative impact on total factor productivity growth. For example, an increase in the number of system engineers involved in a particular software development project can actually promote inefficiency by making communication more difficult. The success of the Linux operating systemwhich has been developed over the Internet by a large number of engineers from all around the world who have contributed their skills free of charge-would appear to be a convincing counterexample, but it should be noted that this type of development scheme was not commonplace in the 1990s.

Also, Minetaki and Motohashi (2009) study the productivity of the Japanese software industry empirically using dataset presented by Informationtechnology Promotion Agency, Japan in 2007. It focuses on the hierarchy structure of this industry and human capital as the same as this study. It categorizes the software companies into four groups by the ratio of 
Am. J. of Economics and Business Administration 2 (1): 73-77, 2010

outsourcing cost to total cost and the ratio of sales within the same industry to total sales. The conclusion is that the human capital accumulation using the Information Technology Engineers Examination can raise the productivity in the group where the ratio of outsourcing cost to total cost is high and the ratio of sales within the same industry to total sales is also high. Our study relies on Minetaki and Motohashi (2009) basically.

Minetaki (2008) attempts to examine whether natural selection mechanism works properly in the Japanese information service industry. It finds very active industries, namely a large number of business starts are observed and at the same time a large number of business failures are also common. The survival ratio of new businesses is quite low, but it improves as firms survive longer. These characteristics are also found in other industries in Japan and other countries. Thus all in all, Japanese industries are not stagnant as some researchers tend to picture them, but rather quite competitive environment of struggle for survival.

\section{MATERIALS AND METHODS}

The framework for analyzing: We utilize the production function of Cobb-Douglas type to investigate the effect of adopting the Information Technology Engineers Examination for the acquirement of knowledge of software development. Dependant variable is value added and independent variables are labor inputs, capital stocks and dummy variable to represent the accumulation of human capital for software development. Further, labor inputs are calculated by multiple numbers of employees and labor hour. Labor inputs consist of two types of employees, namely one is technical staff of programmer or system engineer and the other is non technical staff of clerk or manager. Capital stocks are tangible assets of equipment or structure and intangible asset of software.

We try to estimate following Eq. 1:

$$
\begin{aligned}
\ln \left(\mathrm{Y}_{\mathrm{i}}\right)= & \mathrm{a}_{1} \ln \left(\mathrm{L}_{1, \mathrm{i}}\right)+\mathrm{a}_{2} \ln \left(\mathrm{L}_{2, \mathrm{i}}\right)+\mathrm{b}_{1} \ln \left(\mathrm{K}_{1, \mathrm{i}}\right)+\mathrm{b}_{2} \ln \left(\mathrm{K}_{2, \mathrm{i}}\right) \\
& +\mathrm{c} \text { dum_h } \mathrm{c}_{\mathrm{i}}+\text { constant }+\mathrm{e}_{\mathrm{i}}
\end{aligned}
$$

where, $\mathrm{Y}_{\mathrm{i}}$ represents value added, $\mathrm{L}_{1, \mathrm{i}}, \mathrm{L}_{2, \mathrm{i}}, \mathrm{K}_{1, \mathrm{i}}, \mathrm{K}_{2, \mathrm{i}}$ and $\mathrm{e}_{\mathrm{i}}$ are labor input (programmer and system engineer), labor input (clerk, manager and non-technical staff), capital stock (equipment and structure), capital stock (software) and error term, respectively. In addition, dum_hc $\mathrm{c}_{\mathrm{i}}$ is an indicator function which company to adopt the Information Technology Engineers Examination for the acquirement of knowledge is 1 and other is 0 .
Table 1: Comparison of labor productivity between contractor and subcontractor

\begin{tabular}{ll}
\hline & Labor productivity (Yen) \\
\hline Contractor & 6.415 \\
Subcontractor & 3.722 \\
\hline
\end{tabular}

Table 2: The share of persons who pass the examination to total technical staff

The share of persons who

pass the examination to

total technical staff $(\%)$

Above 0-30

Labor productivity (Yen)

Above $30-70$

3.843

Above $70-100$

Table 3: Basic statistics

\begin{tabular}{lrrrr}
\hline & \multicolumn{1}{c}{ Mean } & \multicolumn{1}{c}{ SD } & \multicolumn{1}{c}{ Min } & \multicolumn{1}{c}{ Max } \\
\hline Value added & 3396.09 & 8310.13 & 9.00 & 65424.97 \\
Labor input $_{1}$ & 648402.40 & 1350195.00 & 5044.00 & 9979058.00 \\
Labor input $_{2}$ & 131843.40 & 311196.90 & 194.00 & 2495233.00 \\
Capital stock $_{1}$ & 1216.14 & 6337.46 & 1.00 & 77482.97 \\
Capital stock $_{2}$ & 280.74 & 2122.41 & 1.00 & 28468.99 \\
\hline
\end{tabular}

The main hypothesis to investigate is that the coefficient of dummy variable to represent the accumulation of human capital for software development is positive at statistically significant level.

Dataset: We use the survey of information service companies by Information-technology Promotion Agency in Japan. This research was practiced at March in 2008.

Table 1 shows the comparison of the productivity of contractor and subcontractor.

Labor productivity is defined as the value added per hour. The productivity of contractor is above 6,000 yen and it is higher than that of subcontractor clearly.

Table 2 shows the relationship between the productivity and the share of persons who pass the Information Technology Engineers Examination. The labor productivity is the highest in the group of the share above $70 \%$. The value of the labor productivity seems to be large difference between the group of the share under $70 \%$ and that of above $70 \%$. The basic statistics are summarized at Table 3 using estimation.

The comparison of the productivity of contractor and subcontractor presents the evidence of the inefficiency of the rigid hierarchy structure in the Japanese software industry.

Also the relationship between the productivity and the share of persons who pass the Information Technology Engineers Examination suggests the importance of human capital because employees study and acquire the knowledge of software development to pass the examination. So the accumulation of human capital could contribute to raise the labor productivity. 
Am. J. of Economics and Business Administration 2 (1): 73-77, 2010

\section{RESULTS AND DISCUSSION}

We estimate the Eq. 1 as above mentioned by using OLS for three cases of total, contractor and subcontractor.

The estimation results are shown in Table 4. The coefficients of labor inputs and capital stocks show the elasticity to value added.

The coefficient of labor input $_{1}$ is statistically significant in each case. This means that the increase of programmers or system engineers can raise the value added. On the other hand, the coefficient of labor input $_{2}$ is not significant in every case and so the increase of clerks or managers cannot raise the value added. We find that here is the difference of types of labor to contribute to value added.

The coefficient of capital input ${ }_{1}$ is not significant in each case. This means that the increase of tangible asset of equipment and structure cannot raise the value added. The coefficient of capital input ${ }_{2}$ that is intangible asset of software capital stock is significant in total case and contractor case, not subcontractor case. This result is very meaningful to us suggesting that the technological progress is embodied to the intangible asset in the contractor and not in subcontractor. It suggests one of the reasons why there is large difference of labor productivity between contractor and subcontractor.

The coefficient of dummy variable to adopt the Information Technology Engineers Examination for the acquirement of knowledge of software development is not significant in contractor. On the other hand it is significant in subcontractor. This is main issue of our empirical study. The employees who work in those firms which adopt the Information Technology Engineers Examination can acquire knowledge of software development, so the accumulation of human capital can raise the value added. The firms of subcontractor enjoy this effect on the productivity. The labor productivity is lower in subcontractor than in contractor as shown in Table 1. Our empirical study implies that the way to increase the productivity in subcontractor is the accumulation of human capital by employee's acquirement of knowledge of software development.

In subcontractor, the level of knowledge of software development has large variety. This matter is as the same within the company in subcontractor. In contractor, companies consider the formal knowledge of software development important and so they adopt many education systems to their employee. In subcontractor, there are companies which consider the formal knowledge important as the same as companies
Table 4: Estimation results

\begin{tabular}{lccc}
\hline & Total & Contractor & Subcontractor \\
\hline Labor input $_{1}$ & $0.67 * * *$ & $0.82 * * *$ & $0.76^{* * *}$ \\
Labor input $_{2}$ & 0.08 & 0.05 & 0.00 \\
Capital stock $_{1}$ & 0.02 & -0.03 & 0.07 \\
Capital stock $_{2}$ & $0.14 * * *$ & $0.12^{* *}$ & 0.08 \\
Dum_hc & $0.38^{* *}$ & 0.11 & $0.54 * *$ \\
Constant & $-3.05^{* * *}$ & $-4.01 * * *$ & $-3.52^{* * *}$ \\
Number of & 184 & 78 & 66 \\
observation & \multicolumn{3}{l}{0.79} \\
Adj. $\mathrm{R}^{2}$ & 0.78 & 0.76 & 0.79 \\
\hline Note: $* * *, * *$ and $*:$ Mean 1, 5 and 10\% significant level. Labor \\
inputs and capital stocks are forms of natural logarithm
\end{tabular}

in contractor, but there are other companies which consider the tacit knowledge more important than the formal knowledge. So they have the tendency of relying on the job training where employees acquire the knowledge for their needs in practice. Our empirical study suggests this method is not efficient. It is necessary for subcontractor to raise the labor productivity to accumulate of human capital having the formal knowledge of software development.

The process of translating of the tacit knowledge which programmers and system engineers have by their selves into the formal knowledge of software development is crucial especially to the subcontractor companies which need the manpower and the upgrade the quality of their employees.

The speed of obsolete of skill embodied to labor is very high because of rapid technological progress in software industry. This is one of reasons why the formal knowledge is important. The Information Technology Engineers Examination offers the opportunity to renewal the knowledge of software development.

Brooks (1995) argues that the time of one programmer is not a perfect substitute for the time of another programmer, which means that a project that takes a single programmer $100 \mathrm{~h}$ to complete cannot be completed in $1 \mathrm{~h}$ by simply assigning 100 programmers to the task. According to Brooks (1995): "Since software construction is inherently a systems effort-an exercise in complex interrelationships-communication effort is great and it quickly dominates the decrease in individual task time brought about by partitioning. Adding more men then lengthens, not shortens, the schedule". Brooks coined the phrase "The Mythical Man-Month" to emphasize his point, which is essentially that an increase in the number of programmers or system engineers can actually have a negative impact on productivity for software firms, particularly in cases where communication among programmers or system engineers plays a vital role. This implies that the exchange of tacit knowledge 
among employees is very difficult and therefore it decreases the productivity consequently.

\section{CONCLUSION}

The increase of the productivity of subcontractor will lead to the structural change of the software industry as a whole. Because the contractor can keep their predominance in the case that the technological level is higher than the subcontractor.

The growth of the service industry has been faster than the economy overall. In particular knowledge intensive services as like software industry represent the growth sector in the economy.

From the view of service innovation, translating of the tacit knowledge into the formal knowledge and sharing the know-how which each programmer or each system engineer has accumulated are important. This process will bring the high productivity.

Widespread outsourcing of core operations is often cited as a defining characteristic of firms in the software industry. One reason for the popularity of outsourcing arrangements may be the particularly rapid pace of technological progress in this industry, which can make it very difficult for a firm to keep up to speed with the latest technologies while relying solely on inhouse resources. For example, whereas the vast majority of programmers used the COBOL language back in the era of mainframe computers as discussed in Baldwin and Clark (1997), the Java programming language is considerably more popular in the current era of ubiquitous personal computers and the Internet (Developed by Sun Microsystems (and originally intended for use with consumer electronics), Java is a platform-independent programming environment that is now widely used on the World Wide Web). To outsource of core operations efficiently, sharing the knowledge of software development is necessary.

In this study we consider the share of persons who pass the Information Technology Engineers Examination to total employees as the proxy of human capital accumulation. But the Information Technology Engineers Examination is not global measurement. To survive in the global competition, it is not enough for the Japanese software firms. On the contrary, Capability Maturity Model (CMM) is the measurement recognized globally. Unfortunately, the Japanese software firms are not evaluated highly by this measurement.

We think the role of the Japanese government's strategy to the software industry is very important now. Since early 2000 the Japanese government has been promoting its "e-Japan Strategy" with a view to revitalizing the Japanese economy via advances in information technology. This strategy places a particular emphasis on "electronic government" as a means of creating new demand for Japan's software industries and thereby placing them on a more equal footing with better-performing hardware manufacturers. It is necessary for the Japanese government to build up the education system of the software development for the purpose of strengthening the power of competition globally.

\section{ACKNOWLEDGMENT}

This study is supported in part by Japan Society for the Promotion of Science: Grant-in-Aid for Scientific Research (B) (21330061) and Grant-in-Aid for Scientific Research (B) (19330056). Any errors that remain are solely the responsibility of the authors.

We are thankful to anonymous referees and participants at the ABEAI 2009 annual conference for helpful comments. Any errors that remain are solely the responsibility of the authors.

\section{REFERENCES}

Brooks Jr., F.P., 1995. The Mythical Man-Month: Essays on Software Engineering Anniversary Edition. Addison-Wesley Publishing Company, Inc., ISBN: 0-201-83595-9, p: 17.

Baldwin, C.Y. and K.B. Clark, 1997. Managing in an age of modularity. Harvard Bus. Rev., 75: 84-93. DOI: $10.1225 / 97502$

Minetaki, K. and K. Motohashi, 2009. Subcontracting structure and productivity in the Japanese software industry. Rev. Socionetwork Strat., 3: 51-65. DOI: 10.1007/s12626-009-0008-8

Minetaki, K., 2008. Analysis of productivity in Japanese information service industries. RCSS Discuss. Paper Ser., 70: 1-23.

Nishimura, S. and K. Minetaki, 2004. Information Communication Technological and Productivity in Japan. Yuhikaku, ISBN: 4-641-16211-5, pp: 231. 